\title{
PERSPECTIVAS DE LEITURA EM SENTIDO CONOTATIVO NO CONTO A MENINA DE LÁ, DE JOÃO GUIMARÃES ROSA $^{1}$
}

\section{READING PERSPECTIVES IN THE CONNOTATIVE SENSE IN THE TALE THE GIRL FROM THERE, BY JOÃO GUIMARÃES ROSA}

VINAGRE, Verônica Falcão de Oliveira. ${ }^{1}$

RESUMO: Este artigo reflete sobre o encontro entre o conto A menina de lá de João Guimarães Rosa e o aluno, leitor no contex to escolar brasileiro. Repensando a prática da leitura baseandose na Conotação como instrumento para a interpretação de textos literários e dissipando o mito da dificuldade ou incompreensão desse tipo de escrita, propõe-se um mapeamento dos termos essenciais para a compreensão do todo textual visando questionar se a conotação favorece a compreensão do conto e se fomenta o entendimento de outros textos desenvolvendo a crítica e a reflexão.

PALAVRAS-CHAVE: Conotação, Leitor, Texto, João Guimarães Rosa, Literatura.

ABSTRACT: This article reflects the meeting between the tale The Girl From There by João Guimarães Rosa and the student, reader in the brazilian school context. Rethinking the reading practice based on connotation as an instrument of literary text interpretation and dissipating the mith of difficulty or noncomprehention of this type of writing. It is proposed a mapping of the essential terms for the comprehention of the whole text in order to question whether the connotation is an advantage for the comprehention of the tale and whether it fosters understanding of others texts by developing the criticism and reflection.

KEYWORDS: Connotation, Reader, Text, João Guimarães Rosa, Literature.

A leitura, atividade rotineira em classes de Língua Portuguesa, demanda dos sujeitos envolvimento com o material trabalhado. Esse envolvimento requer, obviamente,

\footnotetext{
${ }^{1}$ Mestranda. Universidade Federal do Rio Grande do Norte - UFRN.
} 
reconhecimento das palavras empregadas para que o texto se transforme em um todo significativo. Significa dizer que em qualquer texto a construção de significados necessita competências para além de uma leitura desavisada, pois as palavras desempenham funções em determinadas escrituras em que o conteúdo, por seu caráter diverso, parece não fazer sentido, principalmente em textos que permitem várias interpretações como é o texto literário.

Dessa maneira, pensar em texto literário é desdobrar todas as possibilidades oferecidas com o objetivo de construir um pensamento sabendo-se que as escolhas lexicais utilizadas não são aleatórias e possuem uma funcionalidade discursiva. Na realidade, as palavras empregadas no texto entrelaçam-se dentro de um contexto produzindo significado, isso porque um texto se forma a partir da conjugação de vocábulos que se relacionam em torno de um mesmo objetivo comunicativo.

Assim, atingir a interpretação que se deseja por meio das palavras escritas exige habilidade com a língua, no entanto, não implica dizer que o escritor ou o leitor deva ser um profundo conhecedor da Gramática de Língua Portuguesa ou um indivíduo com capacidade de memorização exacerbada para saber grande parte do significado dos vocábulos contidos no dicionário.

A conclusão óbvia que se pode tirar dessas assertivas e objeções a respeito da importância do vocabulário é que, se apenas o conhecimento de palavras não é suficiente para a expressão do pensamento, torna-se igualmente estulto presumir que basta estudar gramática para saber falar e escrever satisfatoriamente. Nenhum professor ignora isso. Não obstante, quase todos nós, por vício, tradição ou comodismo, achamos mais fácil e mais simples dar e mandar decorar mil e uma regrinhas gramaticais malsinadas e inúteis, que vão muito além do mínimo indispensável ao manejo correto da língua. O que acontece é que não sobra tempo para o resto - e infelizmente é nesse resto que está o essencial. (GARCIA, 1997, p. 157)

Nessa perspectiva, ler e compreender é preparar-se para o manejo com as palavras, entender os vocábulos como sugestivos, convidativos e intrigantes. Não se devem encarcerar os sentidos, engessá-los em uma plataforma única e linear, pois os significados são construções que negociam com o leitor, interagem e corroboram a compreensão global do texto. 
Vislumbrando o trabalho com esse material, esta reflexão pretende repensar a prática do ler e compreender baseando-se na conotação como mola mestra à interpretação de textos literários. Nessa proposta, busca-se eliminar o mito de que o texto literário é difícil ou, até mesmo, incompreensível para ser trabalhado em sala de aula. Interessa, pois, analisar o significado no conto A menina de lá de João Guimarães Rosa como ferramenta ao estudo da conotação no contexto escolar brasileiro.

Obviamente, não se pretende apontar erros ou indicar culpados pela pouca utilização ou pela subutilização do conto em sala de aula, pelo contrário, esta reflexão empenha-se em repensar sua utilização na aula viabilizando o contato futuro com outros textos literários em momentos de leituras posteriores, destacando, sobretudo, a temática da conotação como um dos pilares para a compreensão e entendimento do conto tornando o leitor participativo, ativo e construtor de sua autonomia leitora.

A palavra texto, por ela mesma, é bastante comum entre os usuários da língua. Ainda que represente certo temor quando ouvida, pois, ao enunciar essa palavra, associa-se, de imediato, àquelas velhas produções realizadas em salas de aula ou aos textos de obrigatória leitura durante a vida escolar, o usuário da língua sabe que se trata de um recurso da esfera comunicativa. A linguagem é uma forma que os seres humanos possuem para interagir com a realidade que os cerca correspondendo a expectativas, contribuindo e refletindo novos padrões sociais, já que

Quando interagimos através da linguagem (quando nos propomos a jogar o "jogo"), temos sempre objetivos, fins a serem atingidos; há relações que desejamos estabelecer, efeitos que pretendemos causar, comportamentos que queremos ver desencadeados, isto é, pretendemos atuar sobre o(os) outro(s) de determinada maneira, obter dele(s) determinadas reações (verbais ou não verbais). (KOCH, 2001, p. 29)

O texto é, então, a representação do pensamento de forma organizada a ponto de que outro indivíduo, em contato com o material escrito, consiga compreender o universo interior do escritor acompanhando sua linha de raciocínio, tendo em vista o legado cultural, intelectual e ideológico deste, manifestados satisfatoriamente por meio da escrita. Isso porque, as palavras "não criam ideias; estas, se existem, é que, forçosamente, acabam corporificando-se naquelas, 
desde que se aprenda como associá-las e concatená-las, fundindo-as em moldes frasais adequados (GARCIA, 1997, p. 291).

Ratifica-se, assim, que as ideias não são tiradas do nada, na realidade, surgem a partir de concepções de uma determinada época e torna-se necessário corporificá-las para que se eternizem. Ajustá-las às perfeitas formas da escrita para se atingir um objetivo é produção textual, por isso, reside neste ponto a importância da leitura e da escrita: a interação entre leitor e texto. Ler e escrever, portanto, é criar significados, oportunizar reflexões e gerar uma fricção entre um mundo e outro de ideias; é instaurar um diálogo, mesmo que silencioso, entre um "eu" e um "tu"; é estruturar um pensamento em prol da compreensão do outro, de sua aceitação, de sua refutação, de seu respeito ou de seu despeito.

Nesse sentido

Desnuda-se com isso, a real importância da escrita e da leitura (...) É o ato de ler e o aluno interesse, pré-d processo de escrever, entre outros meios, que nos transportam para a reflexão, que nos instigam a pensar sobre nossas vidas, que nos estimulam a querer compreender o mundo se trata de textos lit e inconformar-se com ele. (LUIZ, LUNARDI, ROCCA, SOUZA, LUZ, PISKE, 1996, propósitos em relaçãc p...........

criativa e poetizada de um determinado tema.

Se as palavras, por exemplo, nascem neutras, mais ou menos como estão em estado de dicionário, ao se contextualizarem, passam a expandir valores, conceitos, préconceitos. Nós iremos viver e aprender em contato com outros homens, mediados pelas palavras, que irão nos informar e formar. As palavras serão por nós absorvidas, transformadas e reproduzidas, criando um circuito de formação e reformulação de nossas consciências. (CITELLI, 2001, p. 28)

Dessa forma, o texto de cunho literário apresenta ao leitor não somente as informações diretas e objetivas, mas sim todo um processo de construção e produção de significados. E, essa construção se dá de forma colaborativa entre o texto e o leitor, pois é nessa fricção que os sentidos se estabelecem e o texto ganha significado.

Assim, segundo Pound (1998, p. 32), "Literatura é linguagem carregada de significado". Esse "carregamento" de significados não deve ser entendido apenas em relação aos possíveis significados que o texto possa sugerir, isto é, à mensagem que transmite. Mas também, e principalmente em se tratando de sala de aula, ao como o autor construiu, atribuiu e proporcionou em seus leitores, por meio simplesmente de palavras, tais significados. 


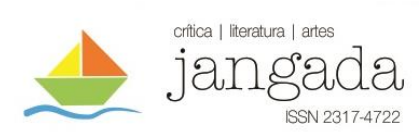

Então, para desfrutar de um texto em que a poesia é a condutora do pensamento, não é necessário ser um perito no assunto, isso significa dizer que as artes (e a Literatura está embutida) são combustíveis humano, como define Barthes (2004, p. 20):

Texto de prazer: aquele que contenta, enche, dá euforia; aquele que vem da cultura, não rompe com ela, está ligado a uma prática confortável da leitura. Texto de fruição: aquele que põe em estado de perda, aquele que desconforta (talvez até um certo enfado), faz vacilar as bases históricas, culturais, psicológicas do leitor, a consistência de seus gostos, de seus valores e de suas lembranças, faz entrar em crise sua relação com a linguagem.

Muito além de simplesmente deflagrar uma realidade, o texto literário apresenta possibilidades que dão ao leitor múltiplos olhares para uma mesma escritura. Ou seja, um mesmo texto apresenta diversas sendas que são trilhadas a partir do ângulo visto pelo leitor. Por isso, a produção literária não esgota seu significado, pelo contrário, multiplica-se e ganha cada vez mais novas significações que irão, paulatinamente, agregando-se e formando outras novas e é esse o fator que propiciará o texto como uma escritura universal e democrática.

A necessidade de comunicação humana fez surgir a linguagem e, por conseguinte, ela se adapta conforme as exigências. Sendo assim, o sentimentalismo e as emoções humanas são retratadas por meio de vários instrumentos artísticos, dentre eles, a própria linguagem.

Em se tratando da construção do texto literário, o escritor, além de lançar mão dos elementos que o envolvem circunstancialmente, vale-se de ferramentas para atingir o seu leitor e transmitir sua mensagem. As informações circunstanciais têm a ver diretamente com a cultura na qual o escritor está inserido ou tenha vivenciado, pois só se escreve sobre aquilo que se conhece.

Somando-se a isso, os elementos constitutivos do texto literário são instrumentos que dão suporte ao escritor para atingir o seu objetivo. Ora, todo texto carrega em si um propósito de ser, portanto, além do fundamental, que são as palavras, existem recursos que embasam o trabalho poético.

Essas ferramentas permitem que o trabalho com as palavras se dê de maneira organizada e apoiada em um bom manejo com o vocabulário para, por fim, atingir o seu leitor da forma que assim desejar. O arranjo com as palavras no texto é o reflexo da escolha vocabular do autor que dispõe desse ingrediente para a construção textual, pois

Jangada | nr. 10, jul/dez, 2017 | ISSN 2317-4722 - 127 | Pá g i n a 
o artista literário trabalha com uma matéria-prima: a palavra. No entanto, a palavra em si não basta para se obter um bom texto; é necessário que ela seja trabalhada num processo de seleção e arrumação vocabular e exploração de significados. Esse processo caracteriza a linguagem poética. A linguagem poética explora o sentido conotativo das palavras, isto é, não o sentido frio e impessoal, "em estado de dicionário", mas sim o sentido alterado, passível de interpretações (NICOLA e INFANTE, 1995, p. 13)

Assim, a escolha vocabular não se dá apenas em termos da denotação, ou seja, “a parte da significação que diz respeito, na linguagem, à representação compreensiva em face do mundo exterior objetivo e do mundo subjetivo interior" (CÂMARA, 1998, p. 92). O sentido das palavras no texto literário não se restringe ao significado automático com que se estabelecem as relações. Ou seja, ao ser pensada ou pronunciada a palavra árvore, automaticamente, são acionados esquemas mentais que fazem uma relação simbólica com a palavra, por isso, mentalmente, visualiza-se a imagem ou os componentes de uma árvore.

O sentido poético extrapola a denotação, mas não a descarta. Ou seja, é a partir do significado primeiro da palavra que se abrem fendas para novas relações. E, fazer associações permite o aprimoramento de uma compreensão mais alargada e menos limitada do contexto no qual se esteja inserido. A árvore, então, não é somente um "vegetal lenhoso cujo caule, o tronco, só se ramifica bem acima do nível do solo" (FERREIRA, 1977, p. 42), mas sim um conjunto de outras significações que, a partir da primeira, permitem a reflexão, a aquisição e a transmissão do conhecimento. Tendo em vista essa exemplificação, ressalta Aristóteles (2006, p. 80) que "descobrir metáforas apropriadas equivale a ser capaz de perceber as relações" e isso pertence ao campo da conotação que é

Parte do sentido de uma palavra que não corresponde à significação stricto sensu, ou seja, o valor representativo como símbolo de um elemento biossocial, mas corresponde à capacidade da palavra de funcionar para uma manifestação psíquica ou apelo. (CÂMARA, 1998, p. 82)

Esse poder de transcender aos seus significados enriquece e fundamenta o trabalho com o texto literário, já que as palavras não permanecem contidas dentro de uma única fôrma como 


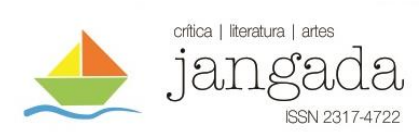

se estáticas fossem. A linguagem literária permite sua elasticidade e garante múltiplos sentidos. Aquela árvore, então composta, stricto sensu, por galhos, folhas e tronco, renasce para uma significação maior, mais interessante e significativa para seu leitor. Portanto,

a mensagem literária é autocentrada, ou seja, o autor, pela organização da mensagem, procura recriar certos conteúdos. Faz isso por meio de múltiplos recursos: ritmos, sonoridades, distribuição das sequências por oposição ou simetria, repetição de palavras ou de sons (rimas), repetição de situações ou descrições (verdadeiras rimas no romance ou conto). (PLATÃO e FIORIN, 1997, p. 351)

Não obstante, para compreendê-la, o leitor também deve estar munido de suas ferramentas, ou seja, o olhar lançado para um texto literário não deve ser o de um sujeito desavisado, pois ele será um dos elementos fundamentais dessa tríade autor-leitor-texto. Ele contribuirá para a construção ou reconstrução dos significados tendo em vista sua perspectiva, seu contexto e seu conhecimento de mundo, isto é, seus dados culturais, por isso,

fruir um texto literário é perceber essa recriação do conteúdo na expressão e não meramente compreender o conteúdo; é entender os significados dos elementos da expressão. No texto literário, o escritor não apenas procura dizer o mundo, mas recriá-lo nas palavras, de modo que, nele, não importa não apenas o que se diz, mas o modo como se diz (PLATÃO e FIORIN, 1997, p. 351).

Falar de texto remete ao ambiente escolar. No Brasil, ainda que haja várias campanhas sobre o quão importante é o hábito da leitura, não há por parte da sociedade um engajamento nesse sentido existindo, também, um dado cultural que consiste em restringir a leitura apenas ao ambiente escolar. Ou seja, um hábito saudável, prazeroso e, sobretudo, educativo, é encarado, socialmente, como obrigação apenas da escola.

Ainda que silencioso, esse consentimento, faz com que os alunos entendam e absorvam a ideia de que ler é restrição e imposição da escola que os obriga a travar contato com textos cansativos, desagradáveis e até inúteis. Resta saber dos professores se

O vocabulário é repassado de obrigações e cobranças: trabalho longo e árduo, atividade exigida, leitura obrigatória... expressões cinzentas e duras, em harmonia com uma escola como a brasileira, amarga e curtida por políticas educacionais

Jangada | nr. 10, jul/dez, 2017 | ISSN 2317-4722 - 129 | Pá g i n a 


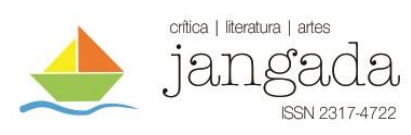

equivocadas. A função desse professor bem-sucedido confina-se ao papel de propagandista persuasivo de um produto (leitura) que, sob a avalanche do marketing e do merchandising, corre o risco de perder, ao menos em parte, sua especificidade.

(LAJOLO, 1993, p. 14)

Esquece-se dessa forma que a leitura é parte integrante da vida de qualquer cidadão seja qual for sua idade ou opção profissional, pois o mundo é feito de textos, de palavras e de elementos que conduzem o leitor ou interlocutor a convencer-se de algo que se queira convencer. Nisto reside a importância da obra literária: ela será sempre uma leitura crítica do real. Mesmo que essa crítica não esteja explícita, o texto coloca o leitor em relação àquela realidade ali expressa e é nessa fricção entre texto e leitor, que este se posiciona naquele contexto. Essa é uma das vantagens do sujeito que se relaciona com textos, estuda-os e refleteos. Mais ainda "a escrita e a leitura são exercícios de liberdade: liberdade no uso da linguagem, esclerosada e estereotipada no uso cotidiano, e liberdade do imaginário, oposto a uma suposta fatalidade da história (PERRONE-MOISÉS, 2000, p. 351)

A leitura, por ser literária, abre fendas nas palavras, isto é, o discurso literário viabiliza várias interpretações possíveis dentro do seu eixo temático. E é nessa abertura das palavras que o leitor por vezes se enrasca nas tramas do significado e passa a considerar o texto literário difícil, pois

lido de maneira fragmentária, um texto pode dar a impressão de um aglomerado de noções desconexas, ao qual o leitor pode atribuir o sentido que quiser. Sem dúvida, há várias possibilidades de interpretar um texto, mas há limites. (PLATÃO e FIORIN, 1997, p. 102)

Tais limites são oferecidos pelo próprio texto, mas para detectá-los há de se perceber os elementos que conduzem a sua interpretação, como ratifica Platão e Fiorin (1997, p. 104):

Dizer que um texto pode permitir várias leituras não implica, de modo algum, admitir que qualquer interpretação seja correta nem que o leitor possa dar ao texto o sentido que lhe aprouver. (...) Sem dúvida, o texto que admite várias leituras contém em si indicadores dessas várias possibilidades.

Jangada | nr. 10, jul/dez, 2017 | ISSN 2317-4722 - 130 | Pá g i n a 


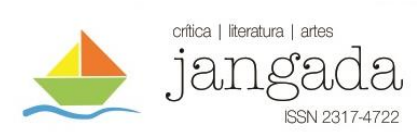

Dessa forma, pode-se dizer que o sentido do texto provém das várias escolhas lexicais do autor e, portanto, a partir das palavras é que o seu significado vai se construir junto ao leitor. Se as preferências lexicais do autor promovem o acompanhamento interpretativo do seu interlocutor, são nessas palavras a chave primeira para a compreensão do todo textual, então

o que é significar? Em sentido geral, qualquer pessoa é capaz de atribuir um significado a uma palavra, desde que faça parte de seu vocabulário. Então, significar é denominar as coisas, reconhecer o objeto ou a ideia a que a palavra se refere; tratase de um processo simples como respirar. Vamos observar, porém, que nem sempre é fácil encontrar todos os objetos referentes para cada denominação, como para os substantivos abstratos (verdade, amor, virtude, por exemplo), ou ainda, reconhecer os sentidos das gradações dos adjetivos (bom, melhor, ótimo, bonito, pior, etc.). (PAULIUKONIS, 2009, p. 14)

E, em um texto literário, cada vocábulo contribuirá para a construção do significado, já que em seus múltiplos sentidos, um se incorporará àquele contexto e imprimirá no interlocutor o encaminhamento para a sua compreensão. Não obstante, se há um escasso conhecimento de vocábulos por parte dos alunos, ocorre, pois, um empecilho no processo de produção de sentido do texto literário. Se o leitor não consegue acessar os sentidos, obviamente, há uma dificuldade em fazê-lo gostar do texto, justamente porque não consegue compreendê-lo.

De forma que um vocabulário escasso e inadequado, incapaz de veicular impressões e concepções, mina o próprio desenvolvimento mental, tolhe a imaginação e o poder criador, limitando a capacidade de observar, compreender e até mesmo de sentir. (GARCIA, 1997, p. 156)

Diferentemente de outras tipologias textuais, o texto literário, por trabalhar as palavras destacando, sobretudo, seus significados, necessita de leitores perspicazes e colaboradores para a criação de sentido. Vale ressaltar que o leitor de textos literários não pode compreender as palavras como estáticas e dicionarizadas, pois se assim for, evidenciará a face mais superficial do vocábulo, não atentando para as outras possibilidades que existem de forma mais aprofundada. 


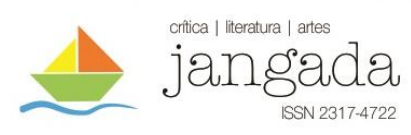

Parece óbvio, mas realizar associações e relações que não estão expressas na superficialidade do texto exige do leitor um trabalho de tessitura de sentidos e estar preparado e disponível para esse labor é o grande desafio encontrado por professores em suas salas de aula. Tendo em vista essa dificuldade, é mister compreender que por mais diversos que sejam, os sentidos das palavras situam-se em dois planos: o da conotação e o da denotação.

Em se tratando da denotação, entende-se que se remete aos significados que estão dicionarizados, ou seja, são os significados imediatos, mais comuns e estáticos para aquele determinado vocábulo.

quando uma palavra é tomada no seu sentido usual, no sentido dito "próprio", isto é, não figurado, não metafórico, no sentido "primeiro" que dela nos dão os dicionários, quando é empregada de tal modo que signifique a mesma coisa para mim e para você, leitor, como para todos os membros da comunidade sociolinguística de que ambos fazemos parte, então se diz que essa palavra tem sentido denotativo ou referencial, porque denota, remete ou se refere a um objeto do mundo extralinguístico, objeto real ou imaginário. A palavra assim empregada é entendida independentemente de interpretações individuais, interpretações de natureza afetiva ou emocional. O seu significado não resulta de associações, não está condicionado à experiência ou às vivências do receptor (leitor, ouvinte). (GARCIA, 1997, p. 162)

Diferentemente da denotação, a conotação alarga o sentido da palavra aliando vocábulo e contexto na tentativa de viabilizar um novo significado. Parte-se, portanto, da base significativa da palavra estendendo o sentido em direção a uma nova interpretação. Por isso, o texto literário não sobrevive sem essa viabilidade, já que são os múltiplos sentidos do vocábulo que favorecem a compreensão do que se quer dizer. Assim, o arranjo de palavras na produção literária não é aleatório justamente por (re)criar um contexto desejado pelo autor. A conotação, portanto:

implica em relação à coisa designada, um espírito, um julgamento, um certo grau de afetividade, que variam conforme a experiência, ou temperamento, a sensibilidade, a cultura e os hábitos do falante ou ouvinte, do autor ou leitor. Conotação é, assim, uma espécie de emanação semântica, possível graças à faculdade de associação de ideias inerente ao espírito humano, faculdade que nos permite relacionar coisas análogas ou assemelhadas. (GARCIA, 1997, p. 163)

Jangada | nr. 10, jul/dez, 2017 | ISSN 2317-4722 - 132 | Pá g i n a 
No rearranjo dos significados, as palavras ganham nova vida e distribuem aos seus leitores as suas novas perspectivas. Sendo assim, um novo panorama se descortina e o trabalho de criação de sentidos recomeça a cada novo olhar ao texto literário. A leitura, definitivamente, é trabalhosa, pois exige concentração, percepção e associação, mas nem todos os leitores estão prontos, principalmente, quando essa atividade é realizada em sala de aula. Não obstante, direcionar a leitura literária destacando sua importância para a compreensão maior do mundo que os cerca, faz com que os alunos, pouco a pouco, apropriem-se do hábito e desenvolvam prazer por sua realização.

Apresentar o texto, captar o que em um primeiro momento se depreendeu e ampliar a leitura em um movimento progressivo e estimulante, corrobora para fomentar a prática da leitura, principalmente, quando o que está em destaque é a possibilidade de interpretação dos alunos. Por isso, o texto bem discutido permitirá que os discentes percebam o quão rico é o mundo literário e construam valores a partir do que se lê.

E é nessa vastidão de palavras e significados que se desvela o para além das palavras e se amplia o significado do que está escrito. Assim, a palavra dicionarizada diz ou insinua o que quer dizer, substitui um termo pré-definido por outro que não imprime diretamente o significado, mas constrói na mente do leitor a imagem sugerida.

Nessa fricção com as palavras, a metáfora é um dos pilares para a construção literária e aliada à linguagem conotativa baseia-se em uma relação de sentido entre o que é comumente conhecido com o estabelecimento de um novo significado. "Metáfora é, então, a alteração do sentido de uma palavra ou expressão quando entre o sentido que o termo tem e o que ele adquire existe uma intersecção" (PLATÃO e FIORIN, 1997, p. 122).

Assim, a leitura do conto A menina de lá, de Guimarães Rosa, por um leitor desavisado pode causar um estranhamento no processo de compreensão do material escrito. Já no título, sugere-se um lugar, por meio da utilização do advérbio "lá". No entanto, durante o percurso da leitura, não fica claro para o leitor onde fica o "lá". É um “lá” imaginário? Já que o dicionário define como

lá ${ }^{1} a d v .1$ Ali, em lugar distante do falante e do ouvinte. 2 Para aquele lugar. 3 Naquele tempo (passado ou futuro). Para lá de Muito. Para lá de forte. [Do port. arc. alá(do lat. $a d$ [prep.] + illac [= 'naquele lugar']), com queda do $a$ inicial.] (BECHARA, 2009, p. 541)

Jangada | nr. 10, jul/dez, 2017 | ISSN 2317-4722 - 133 | Pág i na 
Somente pela (re)leitura do texto é que se pode depreender um sentido para o "lá", pois é o contexto que determina ou sugere o significado. No entanto, é o trabalho do leitor que proporciona a depreensão dos sentidos. Então, o conto lido de forma desavisada pode gerar um estranhamento, pois há uma reunião de vocábulos que contam uma história fantástica ocorrida não se sabe onde. Esse tipo de procedimento gera um desconforto ao leitor e promove a sensação de que o texto é muito difícil para se compreender ou é uma história desinteressante e desagradável.

Na verdade, ainda que não haja uma advertência indicando que o texto é literário, ao ler o material escrito, o leitor já iniciado nos meandros da leitura, pelos elementos fornecidos, percebe que se trata de um texto de cunho literário, pois consegue discernir as informações e identificá-las como tais. É texto, pois

como se pode notar, o texto é um tecido, uma estrutura construída de tal modo que as frases não têm significado autônomo: num texto, o sentido de uma frase é dado pela correlação que ela mantém com as demais. (PLATÃO e FIORIN, 1997, p. 15)

E é literário porque

é conotativo e, assim, cria significados novos. A linguagem em função utilitária aspira a ser denotativa, enquanto a linguagem em função estética procura a conotação. (...) Enquanto a linguagem em função utilitária pretende ter um único significado, a linguagem em função estética é plurissignificativa. (PLATÃO e FIORIN, 1997, p. 351-352)

Considerando o texto como representação do pensamento de forma organizada, uma vez que "uma boa leitura nunca pode deixar de apreender o pronunciamento contido por trás do texto, já que sempre se produz um texto para marcar posição frente a uma questão qualquer" (PLATÃO e FIORIN, 1997, p. 14).

Assim podem-se visualizar as informações:

QUADRO N 1 : CARACTERÍSTICAS PRIMEIRAS CONTIDAS NA SUPERFICIALIDADE DO CONTO

\begin{tabular}{|l|l|}
\hline LUGAR & Por trás da Serra do Mim, Temor-de-Deus; brejo de água limpa \\
\hline
\end{tabular}




\begin{tabular}{|c|l|}
\hline PAI & Pequeno sitiante, lidava com vacas e arroz \\
\hline MÃE & $\begin{array}{l}\text { Urucuiana, nunca tirava o terço das mãos; mesmo quando } \\
\text { matando galinhas ou passando descompostura em alguém }\end{array}$ \\
\hline MARIA, NHINHINHA & $\begin{array}{l}\text { Miúda, cabeçudota, olhos enormes; quieta; nem quatro anos; } \\
\text { calma, imobilidade e silêncio; perpétua e imperturbada; } \\
\text { tranquila; viçosa em saúde }\end{array}$ \\
\hline TIANTÔNIA & \multicolumn{1}{|c}{$?$} \\
\hline
\end{tabular}

Verifica-se nesse destaque que as informações coletadas do texto em um primeiro momento, referente aos personagens e lugar, abarcam dados superficiais, dados meramente informativos. Tais informações pouco contribuem para a compreensão e construção de seu significado, são elementos que alicerçam, mas o restringe por meio de adjetivos de natureza simples. Entretanto, em um processo de releitura, percebe-se uma nova proposta de seleção vocabular que, não descartando os anteriores, amplia seus sentidos e

isso nos leva à conclusão de que, para entender qualquer passagem de um texto, é necessário confrontá-lo com as demais partes que o compõem sob pena de dar-lhe um significado oposto ao que ela de fato tem (PLATÃO e FIORIN, 1997, p. 12).

QUADRO No 2 : CARACTERÍSTICAS OBSERVADAS APROFUNDANDO A LEITURA DA SUPERFICIALIDADE DO TEXTO

\begin{tabular}{|c|l|}
\hline LUGAR & Veio a seca \\
\hline PAI & Menino pidão \\
\hline MÃE & Menina grande \\
\hline MARIA, NHINHINHA & $\begin{array}{l}\text { Referia estórias, absurdas, vagas; respondia, alongada, } \\
\text { sorrida moduladamente; nada a intimidava; } \\
\text { suasibilíssima, inábil como uma flor; respeito por pai e } \\
\text { mãe era mais tolerância; começou a fazer milagres; } \\
\text { queria muito pouco e sempre as coisas levianas e } \\
\text { descuidosas, o que não põe nem quita; queria um } \\
\text { caixãozinho cor-de-rosa, com enfeites verdes brilhantes }\end{array}$ \\
\hline TIANTÔNIA & Repreendeu a menina \\
\hline
\end{tabular}

Já nesse segundo quadro, pode-se perceber que houve uma ampliação das ideias referentes às informações das personagens, ou seja, houve um rearranjo das atribuições aos personagens e lugar. Vale salientar, portanto, que tanto os dados do primeiro quadro quanto os desse segundo coexistem no corpo do texto e há de se ter cuidado e zelo para os perceber, pois 
não se pensa in vacuo. A própria clareza das ideias (se é que as temos sem palavras) está intimamente relacionada com a clareza e a precisão das expressões que as traduzem. As próprias impressões colhidas em contato com o mundo físico, através da experiência sensível, são tanto mais vivas quanto mais capazes de serem traduzidas em palavras - e sem impressões vivas não haverá expressão eficaz. (GARCIA, 1997, p. 155)

Ainda para contribuir para a construção da linguagem poética, que implica o trabalho com as palavras de modo apropriado para gerar sentido e transcender aos significados gerando, pois, as impressões conotativas, podem-se identificar alguns outros elementos que dão subsídios e refletem as escolhas vocabulares convergentes ao tema, uma vez que "nenhum dicionário pode dar todos os sentidos das palavras, em virtude das inúmeras situações (contextos) em que aparecem" (GARCIA, 1997, p. 164):

\section{QUADRO N 3: VOCABULÁRIO INFANTIL NO CONTO}

\begin{tabular}{|l|l|}
\hline \multirow{5}{*}{ LINGUAGEM INFANTIL } & $\begin{array}{l}\text { "Ele xurugou?"/ "Tatu não vê a lua"/ Estórias "da } \\
\text { abelha que se voou para uma nuvem; de uma porção } \\
\text { de meninas e meninos sentados a uma mesa de doces, } \\
\text { comprida, comprida, por tempo que nem se acaba; ou } \\
\text { da precisão de se fazer lista das coisas todas que no dia } \\
\text { por dia a gente vem perdendo"/ "Eu to-u...fa-a- } \\
\text { zendo"/ "Menino pidão...menino pidão"/ "Menina } \\
\text { grande...Menina grande..."/ "Deixa... deixa..."/ } \\
\text { "casacão da noite. - Cheiinhas"/ "estrelinhas pia-pia"/ } \\
\text { "A gente não vê quando o vento se acaba"/ "altura de } \\
\text { urubu não ir"/ "o dedinho chegava quase no céu"/ } \\
\text { "jabuticaba de vem-me-ver"/ "Eu quero ir para lá - } \\
\text { Aonde? - Não sei"/ "O passarinho desapareceu de } \\
\text { cantar"/ "Eeu? Tou fazendo saudade"/ "Eu queria o } \\
\text { sapo vir aqui"/ "Está trabalhando um feitiço"/ "Eu } \\
\text { queria uma pamonhinha de goiabada"/ "Mas, não } \\
\text { pode, ué..."/ "Queria o arco-íris"/ "Adivinhou } \\
\text { passarinho verde? / "passarinho verde pensamento", }\end{array}$ \\
\hline
\end{tabular}

Percebe-se, também, a presença de muitas palavras usadas no diminutivo, o que corrobora o campo semântico referente ao aspecto infantil como "menininha", "Nhinhinha", "sentadinha”, “tolinha”, “cheiinhas", “estrelinhas", “vestidinha”, “dedinho”, "passarinho”, "avezinha", "pulinhos", "pamonhinha”, “pãezinhos”, “quentinha”, “cabecinha”, 
“tamboretinho", “caixãozinho", "filhinha”; comprovando, segundo Platão e Fiorin (1997, p.79), que em um texto "tudo é relação".

Ademais, outros elementos do conto transmitem ao interlocutor informações que o situa quanto à estória. Nota-se, por exemplo, que o ambiente se refere a uma cidade do interior: “... atrás da Serra do Mim"; "quase no meio de um brejo de água limpa”; “o pai... lidava com vacas e arroz"; "a mãe, urucuiana, nunca tirava o terço das mãos, mesmo quando matando galinha ou passando descompostura em alguém"; "...mãe coasse um café forte”; "quintal”; "não o sapo de papo, mas bela rã brejeira"; "chegou uma dona de longe, que trazia os pãezinhos de goiabada enrolada na palha"; "veio a seca, maior, até o brejo ameaçava de se estorricar"; "se não, se acabava tudo, o leite, o arroz, a carne, os doces, frutas, o melado"; “diz-se que da má água desses ares"; "precisavam mandar o recado, ao arraial, para fazerem o caixão e aprontarem o enterro, com acompanhamento de virgens e anjos".

Após o levantamento dos elementos perceptíveis no conto, ratifica-se o fato de se tratar de um texto de caráter literário. O fato é que não é suficiente a reunião desses elementos se não for refletida sua escolha. Veja-se que é o entrelaçamento dessas palavras que, no contexto explicitado pelo conto, produz significado. Assim, o lugar, a menina, a família, as falas e os acontecimentos se entrecruzam e geram informação, pois são as palavras arranjadas, escolhidas e submetidas ao contexto que transformam o pensamento em um texto concreto e significativo. Por isso leitura, então, demanda competência, paciência e direcionamento. O leitor, principalmente em sala de aula, deve ser orientado a buscar nos textos não o sentido imediato encontrado na superfície das palavras, e sim, tentar, encontrar o que de profundo, oculto ou não dito está em cada vocábulo, já que no texto nenhuma escolha é aleatória, tudo é pensado e ali colocado intencionalmente, sugerindo ao leitor um trabalho de manipulação, reflexão e consequente fluidez de sentido, como afirma Platão e Fiorin (1997, p. 114) "um termo ou uma palavra, além do seu significado denotativo, pode vir acrescido de outros significados paralelos, pode vir carregado de impressões, valores afetivos, negativos e positivos".

Assim, do conto em análise, pode-se extrair alguns vocábulos ou expressões que convidam o leitor a parar e ponderar sua utilização denotativa ou conotativa - contribuindo para a construção poética, como expresso em:

QUADRO No 4: DESCOBERTAS CONOTATIVAS - PROCESSO DE LEITURA REFLEXIVA

Jangada| nr. 10, jul/dez, 2017 | ISSN 2317-4722 - 137 | Pág i na 


\begin{tabular}{|c|c|}
\hline Serra do Mim & $\begin{array}{l}\text { A palavra mim pode ser indicativa de introspecção, } \\
\text { pessoalidade? }\end{array}$ \\
\hline Temor-de-Deus & $\begin{array}{l}\begin{array}{l}\text { Faz refererência ao fato de } \\
\text { (transcendental)? }\end{array}\end{array}$ \\
\hline $\begin{array}{l}\text { "Mas, pelo esquisito do juízo } \\
\text { ou enfeitado do sentido" }\end{array}$ & $\begin{array}{l}\text { A forma que Nhinhinha utiliza para expressar-se sugere ao } \\
\text { narrador comentar na ordem inversa o que na ordem direta } \\
\text { seria: juízo esquisito ou sentido enfeitado. Essa opção do } \\
\text { narrador pela utilização do inverso ratifica que a fala da } \\
\text { menina é difícil de entender? }\end{array}$ \\
\hline Riso imprevisto & $\begin{array}{l}\text { Um riso previsto é aquele em que se espera que ocorra; nesse } \\
\text { caso, o narrador indica que não se esperava pelo riso? }\end{array}$ \\
\hline "Tudo muito curto" & $\begin{array}{l}\text { As estórias que Nhinhinha contava eram curtas; a palavra tudo } \\
\text { não sugeriria que suas frases seriam lacônicas, inclusive, } \\
\text { como sua vida? }\end{array}$ \\
\hline $\begin{array}{l}\text { "por tempo que nem se } \\
\text { acabava" }\end{array}$ & $\begin{array}{l}\text { Todo tempo é finito, no entanto, o narrador, via oralidade, } \\
\text { utiliza uma forma de intensificar que a estória dos meninos } \\
\text { sentados a uma mesa de doce durou por muito tempo, então, } \\
\text { caracteriza um tempo de longa duração? }\end{array}$ \\
\hline $\begin{array}{l}\text { "fazer lista das coisas todas } \\
\text { que no dia por dia a gente } \\
\text { vem perdendo" }\end{array}$ & $\begin{array}{l}\text { Que coisas são perdidas no dia a dia? Seria a rotina } \\
\text { esmagadora de ações que se perdem no correr dos dias? Será } \\
\text { que Nhinhinha representa essa efemeridade da vida? }\end{array}$ \\
\hline "Só a pura vida" & $\begin{array}{l}\text { Comentário extremamente significativo. As ações de } \\
\text { Nhinhinha simbolizam a vida nos seus mais puros atos, } \\
\text { prazeres e hábitos? }\end{array}$ \\
\hline $\begin{array}{l}\text { "comia logo a carne ou o } \\
\text { ovo, os torresmos, o do que } \\
\text { fosse mais gostoso e } \\
\text { atraente" }\end{array}$ & $\begin{array}{l}\text { Seria um convite para viver a vida a partir dos pequenos } \\
\text { prazeres que a justificam? }\end{array}$ \\
\hline "inábil como uma flor" & $\begin{array}{l}\text { Essa comparação sugere que a menina não se movia como se } \\
\text { esperava para uma criança de nem quatro anos, mas ainda que } \\
\text { a flor esteja parada, ela perfuma e embeleza a vida de todos, } \\
\text { possuindo também um ciclo de vida e Nhinhinha é isso? }\end{array}$ \\
\hline $\begin{array}{l}\text { "ela apreciava o casacão da } \\
\text { noite" }\end{array}$ & $\begin{array}{l}\text { O que é o casacão da noite? Algo que cobre, esconde, } \\
\text { escurece, protege o dia, as pessoas? }\end{array}$ \\
\hline "estrelinhas pia-pia" & $\begin{array}{l}\text { Estrelas não piam. Essa característica é típica dos pássaros, } \\
\text { mas elas brilham. Então, houve uma relação entre o brilho das } \\
\text { estrelas que por vezes abranda ou intensifica e a ideia dos } \\
\text { pássaros que habitam o céu? }\end{array}$ \\
\hline “Tudo nascendo!" & $\begin{array}{l}\text { Comentário relacionado a "Só a pura vida"? São os ciclos da } \\
\text { vida e do dia? }\end{array}$ \\
\hline $\begin{array}{l}\text { "com o deferir de um } \\
\text { sorriso" }\end{array}$ & $\begin{array}{l}\text { Deferir é consentir. Logo, seria um sorriso significando } \\
\text { concordância? }\end{array}$ \\
\hline
\end{tabular}




\begin{tabular}{|c|c|}
\hline $\begin{array}{l}\text { "o ar estava com cheiro de } \\
\text { lembranças" }\end{array}$ & $\begin{array}{l}\text { Cheiro é uma capacidade olfativa. O que seria cheiro de } \\
\text { lembranças? Lembrança tem cheiro? }\end{array}$ \\
\hline $\begin{array}{l}\text { "A gente não vê quando o } \\
\text { vento se acaba" }\end{array}$ & $\begin{array}{l}\text { Vento não se vê, se sente. Que vento é esse que não se vê? } \\
\text { Quando se acaba? }\end{array}$ \\
\hline $\begin{array}{l}\text { "o que falava, às vezes, era } \\
\text { comum, a gente é que ouvia } \\
\text { exagerado" }\end{array}$ & $\begin{array}{l}\text { Se a fala era comum, por que oportunizava que se ouvisse } \\
\text { exagerado? O que é ouvir exagerado? Ouvir mais do que } \\
\text { deveria? Ou compreender para além das simples palavras } \\
\text { ditas? }\end{array}$ \\
\hline $\begin{array}{l}\text { "o passarinho desapareceu } \\
\text { de cantar" }\end{array}$ & $\begin{array}{l}\text { O motivo do desaparecimento do pássaro é que ele cantou } \\
\text { tanto que desapareceu? Ou que ele passou voando e cantando } \\
\text { até atingir um lugar que já não se consegue ouvi-lo? Ou } \\
\text { porque seu canto foi tão forte que o fez calar? }\end{array}$ \\
\hline "escorregar do t & $\begin{array}{l}\text { Tempo passa e não escorrega. Então, escorrega significa que } \\
\text { deslizou, passou rápido? }\end{array}$ \\
\hline $\begin{array}{l}\text { "Eeu? Tou fazendo } \\
\text { saudade" }\end{array}$ & $\begin{array}{l}\text { Nhinhinha parece ter perfeita noção de que deixaria a vida, } \\
\text { cada momento seria a construção da saudade que se sentiria } \\
\text { dela após sua morte? }\end{array}$ \\
\hline $\begin{array}{l}\text { "disse que ela estava com a } \\
\text { lua" }\end{array}$ & $\begin{array}{l}\text { O que é estar com a lua? Estar junto dela? Realizar uma } \\
\text { viagem até lá ou possuir fases: ora está alegre, ora triste, ora } \\
\text { aborrecido? }\end{array}$ \\
\hline "Ele to & $\begin{array}{l}\text { O que é xurugar? Uma ação verbal em que sentido? Simboliza } \\
\text { o brincar com as palavras típico das crianças? }\end{array}$ \\
\hline $\begin{array}{l}\text { "olhando o nada diante das } \\
\text { pessoas" }\end{array}$ & $\begin{array}{l}\text { Olhar pressupõe observar algo. O que seria olhar o nada? Não } \\
\text { ter atenção? Olhar sem o objetivo de ver? }\end{array}$ \\
\hline $\begin{array}{l}\text { "está trabalhando um } \\
\text { feitiço" }\end{array}$ & $\begin{array}{l}\text { Por que Nhinhinha diz que o sapo está trabalhando um } \\
\text { feitiço? Porque o sapo é elemento mítico das bruxas e } \\
\text { feiticeiras? }\end{array}$ \\
\hline $\begin{array}{l}\text { "Só que queria muito pouco, } \\
\text { e sempre as coisas levianas e } \\
\text { descuidosas, o que não põe } \\
\text { nem quita" }\end{array}$ & $\begin{array}{l}\text { Significa que Nhinhinha não desejava o muito, se contentava } \\
\text { com poucas e desimportantes coisas? Ou que, diferente dos } \\
\text { interesses humanos, valorizava a vida nos pequenos detalhes, } \\
\text { enxergando o que a rotina não permite ao adulto enxergar? }\end{array}$ \\
\hline "Deixa...deixa..." & $\begin{array}{l}\text { Essa fala suscita que Nhinhinha, reticente, sabe do porvir? } \\
\text { Voz de sabedoria? Ou de desleixo? }\end{array}$ \\
\hline "versar conversas" & $\begin{array}{l}\text { Não se desejava abordar conversas sobre os milagres de } \\
\text { Nhinhinha. Mas, há um jogo de palavras que intensifica o } \\
\text { enunciado (versar com+versas)? }\end{array}$ \\
\hline "refrescação" & $\begin{array}{l}\text { Esse substantivo criado sugere uma intensificação no ato de } \\
\text { refrescar? Ou une duas palavras refresca+ação, que sugeriria } \\
\text { a ação de refrescar? }\end{array}$ \\
\hline "deputados de um reino" & $\begin{array}{l}\text { O canto dos pássaros, passada a chuva, significa que a alegria } \\
\text { era tamanha que lhes concedia a sensação de importância } \\
\text { naquele local? }\end{array}$ \\
\hline
\end{tabular}




\begin{tabular}{|l|l|} 
"má água desses ares" & Ares seria lugar? \\
\hline "muitas diversas dores" & Intensifica as dores com a perda de Nhinhinha. \\
\hline "um de-repente enorme" & $\begin{array}{l}\text { De repente significa uma ação surpreendente, mas ligeira. Um } \\
\text { de-repente enorme seria o prolongamento da sensação de } \\
\text { surpresa? }\end{array}$ \\
\hline "Santa Nhinhinha." & $\begin{array}{l}\text { Por que Nhinhinha era considerada santa? Pela idade } \\
\text { prematura com a qual morreu? Pelas ações de milagre? Pela } \\
\text { presença misteriosa, perturbadora e enigmática que vivia em } \\
\text { sua família? Pelas frases sábias que proclamava vez por outra? }\end{array}$ \\
\hline
\end{tabular}

Com os comentários relativos a essas expressões retiradas do conto, pode-se depreender que a linguagem literária, extremamente conotativa, sugere, mas não diz; suscita, mas não esclarece. E é nesse jogo que os sentidos se constituem na trama textual.

Os sentidos atribuídos aos elementos destacados do texto estão identificados por meio de perguntas que não fecham as significações, pelo contrário, tentam aproximar-se dos significados para que o conto ganhe relevância no que tange à sua compreensão, já que "o que importa, para uma boa leitura, não é apenas identificar a escolha feita pelo autor, mas verificar qual é a função que ela tem no sentido do texto” (PLATÃO e FIORIN, 1997, p. 93).

Por isso, os questionamentos sugeridos baseiam-se sempre "em algum tipo de relação que o produtor do texto vê entre o significado habitual e o significado novo", segundo Platão e Fiorin (1997, p. 121), formando metaforicamente um sentido não apropriado ou até mesmo inadequado se utilizado o do dicionário, como em "disse que ela estava com a lua".

Nessa organização constitui-se o sentido poético, aquele que extravasa o significado primeiro e imediato das palavras. Também é nesse aspecto que reside a dificuldade no trabalho com textos literários em sala de aula, pois a compreensão primordial é a de que esse tipo de material não deve ser lido com descuido, e sim de maneira colaborativa para a criação de significados.

Como se pode notar, o conto A menina de lá não é um texto difícil de se compreender, o que ocorre é que o levantamento de hipóteses, como foi feito por meio das perguntas sugeridas, deve servir como uma proposta para o trabalho de leitura em sala de aula, já que são esses levantamentos suscitados que facilitam o encontro prazeroso entre o leitor e o conto. Isso porque 


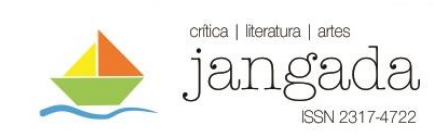

A recorrência de traços semânticos estabelece a leitura que deve ser feita do texto.

Essa leitura não provém dos delírios interpretativos do leitor, mas está inscrita como virtualidade (possibilidade) no texto. (PLATÃO e FIORIN, 1997, p. 102)

Diferente do que se possa pensar, o conto sugere, ou seja, a relação com a significação deve partir sempre do próprio material literário, isto é, do próprio conto, não devendo tentar compreendê-lo engessando-o em definições categóricas, mas deixando que os sentidos pululem, saltem aos seus leitores.

Para isso, é a conotação o ponto de partida fundamental para a leitura e compreensão do conto, não sendo possível ignorar este trabalho, pois o sentido literal das palavras não pode ser usado como significativos em texto que necessite reflexão quanto à utilização dos vocábulos. De forma mais ampla e aprofundada, se

a significação de uma palavra não é a mesma para mim e para você, leitor, como talvez não o seja também para todos os membros da coletividade de que cada um de nós lhe possa dar, se a palavra não remete a um objeto do mundo extralinguístico mas, sobretudo, sugere ou evoca, por associação, outra(s) ideia(s) de ordem abstrata, de natureza afetiva ou emocional, então se diz que seu valor, i.e., seu sentido, é conotativo ou afetivo. (GARCIA, 1997, p.162)

Trabalhar o conto na perspectiva da denotação gera um não sentido global para a leitura. Ou seja, buscar o que quer dizer não contribui para o entendimento do material literário. Mais do que pensar o que quer dizer, o conto deve ser lido na perspectiva do que significam as palavras empregadas, pois a busca pelo sentido literal, por vezes, não soma ao todo significativo.

Portanto, com o objetivo de desmistificar o trabalho com textos literários na escola e resgatar a sua importância para o desenvolvimento da habilidade leitora em virtude da desenvoltura com textos vindouros em contextos distintos, foi escolhido o conto de Guimarães Rosa para convidar os professores e alunos a refletirem sobre a utilização e importância de se ler Literatura em sala de aula.

Assim, quem é Nhinhinha? O que significa o todo textual? Por que as escolhas lexicais foram essas e não outras? Por que existem palavras no diminutivo? Por que há expressões que 


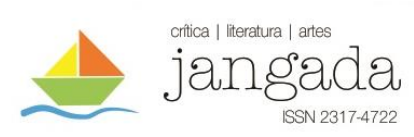

não possuem significado e nem são palavras dicionarizadas, como “xurugou”? Por que se passa em um interior, como prova a palavra "arraial”?

Para todas essas respostas, o texto sugere encaminhamentos e a construção se dá, exatamente, pela relação estabelecida que se faz a partir das sugestões imbricadas em cada palavra. Por isso, como o texto gira em torno de Nhinhinha e de seu universo infantil, as palavras ganham o sufixo no diminutivo “-inha”; as frases de Nhinhinha são sempre incompreensíveis a princípio; a natureza é observada porque se vive no interior onde há brejo e sapo, valorizando-se o céu, os pássaros, a chuva, o arco-íris e as estrelas.

Repara-se que o universo de Nhinhinha é simples: a casa, o quintal, a natureza, a mãe, o pai, a tia e seu pensamento. Este último atributo de Nhinhinha é humilde: ela não sonha, nem se revolta com o que tem ou com o que corre o risco de perder pela estiagem; pelo contrário, tudo é contentamento. O fazer de Nhinhinha é parado, pois ela é quieta, diferente de crianças de sua idade. Vale refletir: é um fazer parado ou um parar para fazer?

Certamente, pela maneira que vive e pelas reflexões que faz: "só a pura vida", "comia logo a carne ou o ovo, os torresmos, o do que fosse mais gostoso e atraente"; "inábil como uma flor"; "tudo nascendo"; "tou fazendo saudade"; "olhando o nada diante das pessoas"; "só que queria muito pouco, e sempre as coisas levianas e descuidosas"; “deixa...deixa...”; "refrescação"; percebe-se que ela não era uma menina comum, principalmente, quando adivinha sua morte.

Então quem é essa menininha? É óbvio que não se pode fechar o significado do conto com apenas um direcionamento, pois o texto, por ser literário, demanda vários sentidos oriundos do que as palavras emanam ao leitor. Porém, pela efemeridade da menina, pode-se pensar que ela é a representação da temática e da simplicidade da vida, pois seus valores são básicos e essenciais, e sua permanência no mundo foi ligeira. O procedimento básico que se utiliza o autor para criar o efeito desejado no leitor e caracterizar a menina é a metáfora. A criação de sentidos e a utilização de palavras cujo campo semântico aponta para vida, infância e transcendência, justifica as escolhas vocabulares.

Obviamente, o estudo do conto em sala de aula pode gerar insegurança por parte dos discentes, já que não há um encaixe perfeito para os significados, ou seja, não se compreenderá o material consultando um dicionário, uma vez que cada vocábulo não é rígido e com o sentido encerrado em si mesmo, pelo contrário, a cada palavra, outras relações são postas. 


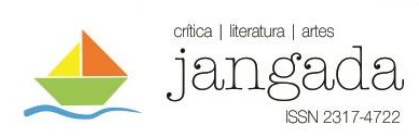

O texto literário, então, é não somente um agrupamento de palavras metaforizadas, mais ainda: um texto cujo suporte para a sua escritura está centrado em um grande processo de burilamento das palavras que chegam ao leitor para organizar e estruturar o pensamento em acordo com o que lhe é ofertado.

A riqueza do texto literário está exatamente neste ponto: quando se diz, por exemplo, que "ela estava com a lua", não significa que ela estava ao lado da lua, mas é uma expressão que deve ser observada com zelo por parte dos leitores para que os sentidos se entrelacem de forma fluida e relevante para a tessitura do texto. Gera-se, portanto, o significado de que a menina, naquele momento, apresentava-se como a lua: fases que podem abarcar o sentido de tristeza e aborrecimento.

Com isso, são as pistas fornecidas pelo texto em seu contexto que favorecem ao leitor a produção do significado. No conto, o mundo percebido aos olhos de Nhinhinha, se apresentava mais vivo, mais rico que o percebido pelo olhar dos adultos que, quase sempre é embaçado pelo desencanto e pela rotina.

Descarta-se, dessa maneira, a impressão e o estigma de que o texto literário é difícil ou até impossível de se trabalhar em sala de aula, uma vez que a forma de envolvimento com o conto, o encaminhamento e a pré-disposição são elementos fundamentais para a leitura que, ao ser analisada por esse enfoque, imprimirá no leitor a possibilidade de ampliação e capacitação para textos vindouros, contribuindo assim, para a interpretação de textos fundamentais a sua própria interação como cidadão em uma sociedade que carece de seres humanos reflexivos e pensantes.

Portanto, torna-se necessário dissipar a noção de dificuldade de leitura do conto porque compreendê-lo é difícil. Pelo contrário, o texto oferece suporte para seu entendimento, já que há dentro dele de maneira organizada, viva e latente reflexões adormecidas esperando serem despertadas por um leitor que seja ávido e capaz de criar novos significados pluralizando seu mundo de ideias.

Obviamente, não é fácil. No entanto, é preciso começar e, certamente, essa mudança ocorrendo de maneira gradual, não trará danos aos sujeitos envolvidos, não gerará questionamentos nem assombro por parte dos alunos, nem insegurança por parte do professor.

Chama-se atenção, aqui nesta reflexão, a uma nova maneira de olhar o texto literário como fonte de um trabalho verdadeiramente significativo em que o professor, como fomentador da experiência vivenciada entre leitor e texto, proporcione esse contato sem haver perda nem 


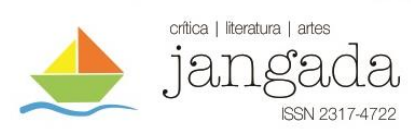

engessamento do sentido poético, já que este necessita encontrar corações e mentes abertos à receptividade, criatividade e aceitação de desafio.

\section{REFERÊNCIAS BIBLIOGRÁFICAS}

ACADEMIA BRASILEIRA DE LETRAS. Biografia de João Guimarães Rosa. Disponível em: <www.academia.org.br/abl/cgi/>. Acesso em: 20/03/10. [s.d.]

ARISTÓTELES. Arte Poética. São Paulo: Martins Claret, 2006.

BECHARA, Evanildo. Minidicionário da Língua portuguesa. Rio de Janeiro: Editora Nova Fronteira, 2009.

BARTHES, Roland. O prazer do texto. Trad. J. Guinsburg. $4^{\text {a }}$ ed. São Paulo: Perspectiva, 2004. CAMARA JR, J. MATTOSO. Dicionário de Linguística e Gramática. Petrópolis: Vozes, 1998. CITELLI, Adilson. Linguagem e Persuasão. São Paulo: Ática, 2001.

FERREIRA, Aurélio Buarque de Holanda. Minidicionário da Língua Portuguesa. Rio de Janeiro: Editora Fronteira, 1977.

GARCIA, Othon M. Comunicação em prosa moderna. Rio de Janeiro: Fundação Getúlio Vargas, 1997.

KOCH, Ingedore Villaça. A inter-ação pela linguagem. São Paulo: Contexto, 2001.

LAJOLO, M. A leitura na escola. In: . Do mundo da leitura para a leitura do mundo.

São Paulo: Ática, 1993. pp. 14-16.

LUIZ, Augusto; LUNARDI, Geovana M.; ROCCA, Jefferson S. Della; SOUZA, Julia L.; LUZ, Lilian; PISKE, Regina. Reminiscências de escritores em desenvolvimento: o processo de escrita do ponto de vista dos alunos. In: BIANCHETTI, L. (Org.) Trama e texto. V.I. São Paulo: Plexus, 1996. pp. 182-189.

MAINGUENEAU, Dominique. Elementos de lingüística para o texto literário. Trad. Maria Augusta Bastos de Matos. São Paulo: Martins Fontes, 1996 (Coleção Leitura e Crítica).

MARCUSCHI, Luiz Antônio. Da fala para a escrita. São Paulo: Cortez, 2005.

NICOLA, José de; INFANTE, Ulisses. Análise e interpretação de poesia. São Paulo: Scipione, 1995.

PAUlIUKONIS, Maria Aparecida Lino. Curso de Língua Portuguesa: da teoria à prática, Semântica e Léxico do Português. 2 ed. Rio de Janeiro: Fundação Trompowsky, 2009.

PLATÃo E FIORIN. Para entender o texto. São Paulo: Ed. Brasiliense, 1986.

PERRONE-MOISÉS, L. Consideração intempestiva sobre o ensino de literatura. In: Inútil poesia. São Paulo: Companhia das Letras, 2000. p. 345-351.

POUND, Ezra. Abc da Literatura. Trad. Augusto de Campos e José Paulo Paes. São Paulo: Cultrix, 1998.

ROSA, João Guimarães. Primeiras Estórias. 15 ed. Rio de Janeiro: Nova Fronteira, 2001.

Jangada | nr. 10, jul/dez, 2017 | ISSN 2317-4722 - 144 | P á g i n a 